\title{
Anesthetic management during cochlear implant surgery on a child with congenital long QT syndrome
}

Ferda YAMAN ( $\sim$ ferdayaman@gmail.com )

Eskişehir Osmangazi Üniversitesi Tıp Fakültesi https://orcid.org/0000-0001-6847-1720

Nurdan Baydogan

University of Eskişehir Osmangazi, Department of Anesthesiology and Reanimation

Armağan İncesulu

Department of Otorhinolaryngology, University of Eskişehir Osmangazi

Ayten Bilir

Department of Anesthesiology and Reanimation, University of Eskişehir Osmangazi

\section{Case Study}

Keywords: Congenital long QT syndrome, cochlear implant, pediatric anesthesia, rocuronium, sugammadex

Posted Date: August 26th, 2020

DOl: https://doi.org/10.21203/rs.3.rs-61503/v1

License: (9) This work is licensed under a Creative Commons Attribution 4.0 International License. Read Full License 


\section{Abstract \\ Background}

Long QT syndrome (LQTS) is an inherited disorder of the heart's electrical activity that may also be associated with malignant arrhythmia and cause sudden death. In addition to this inherited condition, several commonly used anesthetic drugs can prolong the QT interval. The clinical symptoms of LQTS are heart palpitations, syncope, anoxic seizures secondary to ventricular arrhythmia, and torsades de pointes.

\section{Case:}

We present here a 17-month-old male patient with bilateral sensorineural hearing loss who underwent general anesthesia for a cochlear implant. The surgical team was advised about the possible risks of using local anesthesia without adrenaline. A defibrillator, which was checked for pediatric use, was made available in the operating room. After the vascular access was opened, the patient was provided with induction propofol, remifentanil, and rocuronium, and anesthesia was maintained using an intravenous anesthetic. No cardiac arrhythmia was observed in the patient, whose muscle relaxant effect was reversed using sugammadex.

\section{Discussion}

LQTS patients have developed arrhythmia and sudden cardiac arrest from administration of sevoflurane and neostigmine during anesthesia. The application of intravenous anesthetics was preferred to maintain anesthesia for this patient and was safely applied. In addition, a defibrillator was available for immediate use during the perioperative period.

\section{Conclusion}

Anesthesia can be safe by using intravenous rocuronium and sugammadex and local anesthetic without adrenaline.

\section{Introduction}

Long QT syndrome (LQTS) is an inherited condition that causes primary arrhythmia and that affects 1 out of every 2,000 otherwise healthy babies (1). The condition is characterized by the slow depolarization of the cardiac ion channel, which is observed on an electrocardiogram (ECG) as a prolonged QT interval, secondary to a delayed repolarization of the action potential on the cardiomyocyte membrane (2). Sudden cardiac death is observed in $10-12 \%$ of patients with LQTS and a mortality rate of $21 \%$ is expected within 1 year of the first syncopal episode; however, there is treatment that can dramatically reduce these risks $(3,4)$. A recessive form of LQTS was identified by Jervell and Lange-Nielsen in 1957 to 
be associated with a child's deafness, and an autosomal dominant familial form was identified by Romano in 1963 and Conor Ward in 1964. Schwartz and Locati (1985) were the first to publish studies on the natural history of the disease and noted a $71 \%$ mortality rate in patients who were left untreated after the first syncope. That mortality rate has since been greatly reduced to $0.3 \%$ with appropriate medical treatment $(4,5)$.

The QT interval can also be prolonged by several commonly used anesthetic drugs. During the perioperative period, frequent and sudden increases in sympathetic stimulation combined with administration of drugs that prolong the QT interval can create a substrate for development of malignant arrhythmias.

\section{Case}

With the family's permission to study and report in the literature, a 17-month-old male patient with bilateral sensorineural hearing loss with congenital LQTS was to undergo a cochlear implant and referred to the anesthesia outpatient clinic. From information gathered from the patient's relatives, we learned that the father, brother, grandfather aunt, and close relatives also had LQTS, and that the younger brother was physically and hearing impaired and had already had bilateral cochlear and pacemaker implants. An older brother had no medical abnormalities. The patient had a history of syncope at $37 \mathrm{~d}$ and the causes were investigated by pediatric cardiologists because of the family history. The patient's echocardiograph showed a normal ejection fraction, and he was prescribed $3 \mathrm{mg} / \mathrm{kg} / \mathrm{d}$ propranolol $\mathrm{HCl}$ (Dideral ${ }^{\circledR}$ ) after a diagnosis of LQTS based on the prolonged QT interval observed on his electrocardiogram (ECG) (QT = 0.459), and it was noted that the patient complied with his medication regularly. There was no cardiological inconvenience for the implant surgery as long as there was close monitoring, a supply of intravenous (IV) magnesium on hand, anesthetics that did not prolong the QT interval, and continued us of beta-blockers. In the preoperative patient evaluation, the vital signs were normal, mouth opening was good, there was no restriction in head and neck movements, and there were no pathologies in the other physical examination findings. Laboratory tests showed that hemoglobin levels were $9.7 \mathrm{~g} \mathrm{dL} /-\mathrm{L}$, the hematocrit ratio was $31.2 \%$, platelet levels were $492000 / \mathrm{mm}^{3}$, and that other electrolyte and biochemistry results were within normal ranges. Relatives of the patient were informed about the risks of anesthesia and informed patient consent was obtained from them for the intervention. The patient was not premedicated on the morning of the intervention. Sevoflurane induction was applied to the patient for vascular access. A defibrillator, which was checked for use on pediatric patients, was made available in the operating room. After opening the vascular access route, $1 \mathrm{mg} / \mathrm{kg}$ lidocaine, $3 \mathrm{mg} / \mathrm{kg}$ propofol, 0.5 $\mu \mathrm{gr} / \mathrm{kg}$ remifentanil, and $0.5 \mathrm{mg} / \mathrm{kg}$ rocuronium bromide were administered intravenously in induction. During maintenance, $50 \mathrm{mcg} / \mathrm{kg} / \mathrm{min}$ propofol along with a mixture of $50 \%$ oxygen and $50 \%$ air and $0.05 \mathrm{mg} / \mathrm{kg} / \mathrm{min}$ remifentanil infusion (total intravenous anesthesia (TIVA) was applied. The surgical team was warned about the use of local anesthesia without adrenaline. No complications were observed during the induction and surgical procedure. The patient's vital signs remained stable, and there was no rhythm or interval changes during heart monitoring. The intervention time was recorded as $2 \mathrm{~h} 40 \mathrm{~min}$. 
Toward the end of the surgical procedure, for postoperative pain $120 \mathrm{mg}$ paracetamol and $15 \mathrm{mg}$ phenobarbital (Paranox ${ }^{\circledR}$ ) rectally administered. TIVA was discontinued and the effect of the muscle relaxant was reversed by giving $2 \mathrm{mg} / \mathrm{kg}$ sugammadex intravenously. The patient was taken to the recovery room after comfortable awakening and extubation and was monitored for $2 \mathrm{~h}$. The patient did not experience any medical problems after the surgery and was delivered to the otolaryngology service. The surgical service doctor reported no problems in service follow-up.

\section{Discussion}

Jervell and Lange-Nielsen syndrome is an autosomal recessive rare form of LQTS that affects between 1 in 1,000,000-4,000,000 people, is highly malignant, and is associated with bilateral sensorineural deafness. This syndrome was first characterized in 1957 by Jervell and Lange-Nielsen, who described a family comprising 4 of 10 children who suffered from deafness and sudden syncopal spells. Three of the four children demonstrated a prolonged Q-T interval on their ECGs; the fourth child died before an ECG could be obtained (6). The congenital deafness associated with Jervell and Lange-Nielsen syndrome occurs only when two mutant genes are inherited; these mutant genes are known to impair electrical conduction of the auditory nerves and are associated with a more severe form of the disease and increased risk of sudden cardiac death. Genetic testing was not conducted on the patients we studied; diagnosis of LQTS was made when the patient was $37 \mathrm{~d}$ old after experiencing syncope and based on a family history of the condition.

During the preoperative evaluation, any electrolytes given should be evaluated because abnormalities, such as hypokalemia, hypomagnesemia, and hypocalcemia, associated with them can increase the risk of delayed repolarization and may predispose patients to developing ventricular arrhythmias. Hypokalemia and hypocalcemia are independent risk factors associated with a prolonged QT interval. Although electrolytes should be monitored closely, it is reasonable to consider treatment with $30 \mathrm{mg} / \mathrm{kg}$ magnesium given its low risk of toxicity and stabilizing effect on the myocardium (7). There was no electrolyte imbalance in this case, but magnesium was prepared for possible ventricular tachyarrhythmia (torsades de pointes [TdP]).

In a study of 158 anesthetics used on patients with LQTS, volatile agents were used to some degree in $81 \%$ of cases and their use was not related to the development of TdP. In practice, many published accounts of anesthesia used on children with LQTS, including the largest published case series comprising 103 children, demonstrated that sevoflurane anesthesia can be safely administered to these patients without adverse effects (7). It has been suggested that continuation of beta-blocker therapy during the perioperative period may protect against TdP development that is related to an induced prolonged QT interval; however, there are case reports developing torsades de point, patients with LQTS may be more susceptible than different genotypes to arrhythmias induced by volatile agents; therefore, volatile agents should either be avoided altogether or used with great caution in these patients (8). In this case, we gave the patient a very low dose of sevoflurane before opening the vascular access and stopped the sevoflurane after induction with propofol. Lidocaine was administered before intubation to take 
advantage of its arrhythmogenic effect. During the surgery-preparation stage, esmolol, magnesium, and the defibrillator were prepared for treatment of TdP.

We did not administer any premedication before the surgery, but we administered $120 \mathrm{mg}$ paracetamol and $15 \mathrm{mg}$ phenobarbital (Paranox) rectally to prevent pain-related agitation during the postoperative period. During surgery, care was taken not to increase the Valsalva maneuver and ventilator pressures.

Patients with congenital LQTS are at increased risk for developing lethal arrhythmias associated with surgery, and this risk is greatest during periods of increased sympathetic stimulation (i.e., laryngoscopy and emergence); however, they can be safely managed with the appropriate preparation, attention to and selection of intra- and postoperative management, and close monitoring. The control of symptoms before surgery and continued use of a beta blocker is fundamental to safe perioperative care. Close hemodynamic monitoring, avoidance of any drugs that prolong the QT interval, maintaining adequate anesthesia and adequate analgesics, normocarbia, normothermia, and normovolemia are important considerations for intra- and postoperative care. Halogenated volatile anesthetics known to prolong the corrected QT interval, also succinylcholine, pancuronium, neostigmin, atropine, and adrenalin, should be avoided $(9,10)$. In our case, rocuronium, sugammadex, propofol, and remifentanil were administered as safe anesthetics.

\section{Conclusion}

Anesthesiologists must be prepared to recognize and promptly treat tachycardia, $\mathrm{TdP}$, and arrhythmias should they occur during surgery on patients with LQTS. Anesthesia can be safely administered by taking precautions against perioperative complications. Children with sensorineural hearing loss should be alert for long QT syndrome perioperatively.

\section{Abbreviations}

LQTS: Long QT Syndrome

TdP: torsades de pointes

\section{Declarations}

\section{Conflict of Interest}

No conflicts of interest were acknowledged.

\section{Ethics approval and consent to participate:}

The parents of patient was informed and also written informed consent form was obtained. 


\section{Consent for publication:}

This case report was submitted for publication after the family was informed of our intentions, and their permission was obtained and also written informed consent was obtained from the patient for publication of the case details.

\section{Availability of data and materials:}

NA (Not applicable).

\section{Competing interests:}

The authors declare that they have no competing interests.

\section{Funding:}

No funding.

\section{Authors' contributions:}

Ferda Yaman was performed the preparation of the patient and management of anesthesia and the article was written by Ferda Yaman. The patient was analyzed and interpreted the patient data regarding the cardiac disease by Nurdan Baydoğan at the preoperative evalaution.

Dr Armagan Incesulu performed the coclear implantation of the patient and have a major role in the perioperative period. Dr Ayten Bilir was revised it. All authors read and approved the final manuscript."

\section{References}

1. Schwartz PJ, Stramba-Badiale M, Crotti L, Pedrazzini M, Besana A, Bosi G, Gabbarini F, Goulene K, Insolia R, Mannarino S, Mosca F. Prevalence of the congenital long QT syndrome. Circulation. 2009 Nov;3(18):1761. 120(.

2. Schwartz PJ, Ackerman MJ, George AL, Wilde AA. Impact of genetics on the clinical management of channelopathies. J Am Coll Cardiol. 2013 Jul;16(3):169-80. 62(.

3. Priori SG, Schwartz PJ, Napolitano C, Bloise R, Ronchetti E, Grillo M, Vicentini A, Spazzolini C, Nastoli J, Bottelli G, Folli R. Risk stratification in the long-QT syndrome. New England Journal of Medicine. 2003 May 8;348(19):1866-74.

4. Schwartz PJ. Idiopathic long QT syndrome: progress and questions. American heart journal. 1985 Feb 1;109(2):399-411.

5. Staudt GE, Watkins SC. Anesthetic considerations for pediatric patients with congenital long QT Syndrome. Journal of Cardiothoracic and Vascular Anesthesia. 2019 Jul 1;33(7):2030-8. 
6. Wallace E, Howard L, Liu M, O'Brien T, Ward D, Shen S, Prendiville T. Long QT syndrome: genetics and future perspective. Pediatric cardiology. 2019 Aug 22:1-2.

7. Whyte SD, Nathan A, Myers D, Watkins SC, Kannankeril PJ, Etheridge SP, Andrade J, Collins KK, Law $\mathrm{IH}$, Hayes J, Sanatani S. The safety of modern anesthesia for children with long QT syndrome. Anesthesia \& Analgesia. 2014 Oct 1;119(4):932-8.

8. Kumakura M, Hara K, Sata T. Sevoflurane-associated torsade de pointes in a patient with congenital long QT syndrome genotype 2. J Clin Anesth. 2016 Sep;1:33:81-5.

9. Kies SJ, Pabelick CM, Hurley HA, White RD, Ackerman MJ. Anesthesia for patients with congenital long QT syndrome. Anesthesiology: The Journal of the American Society of Anesthesiologists. 2005 Jan;102(1)(1):204-10.

10. Pleym H, Bathen J, Spigset O, Gisvold SE. Ventricular fibrillation related to reversal of the neuromuscular blockade in a patient with long QT syndrome. Acta anaesthesiologica scandinavica. 1999 Mar;43(3):352-5. 